\title{
PROSPECTS FOR REMOTELY PILOTED AIRCRAFT SYSTEMS IN AREA-WIDE INTEGRATED PEST MANAGEMENT PROGRAMMES
}

\author{
D. BENAVENTE-SÁNCHEZ1 ${ }^{1}$ J. MORENO-MOLINA ${ }^{1}$ AND \\ R. ARGILÉS-HERRERO ${ }^{2}$
}

\author{
${ }^{1}$ Embention, Alicante, Spain; embention@embention.com \\ ${ }_{2}^{2}$ Insect Pest Control Section, Joint FAO/IAEA Division of Nuclear Techniques in Food \\ and Agriculture, Vienna, Austria; R.Argiles-Herrero@iaea.org
}

\begin{abstract}
SUMMARY
The scientific and technical advances achieved in recent years in the technology for remotely piloted aircraft systems (RPAS) and the approval of new regulatory frameworks in several countries have allowed the commercial expansion and use of these flying robots for different civil applications, including agriculture. The present review discusses the opportunities for the use of the RPAS in area-wide integrated pest management (AW-IPM) programmes within the current technical and legal constraints. These include targeted insecticide applications of hotspots in fruit fly and mosquito pest management programmes, aerial release of sterile males in mosquito and tsetse control programmes, and aerial release of parasitoids. The advantages of the RPAS technology - accuracy, increased safety and cost-efficiency for small and medium scale operations - are counterbalanced by its limitations at the technical level - reduced payload and flight duration - as well as at the regulatory level - mandatory special operational permits from regulatory agencies for operations beyond the visual line of sight.
\end{abstract}

Key Words: RPAS, unmanned aircraft, UAS, drones, regulation, sterile insects, parasitoids, pest control

\section{INTRODUCTION}

Area-wide integrated pest management (AW-IPM) programmes aim at controlling a given pest at a geographic scale, targeting the whole pest population (Hendrichs et al. 2007). By definition, there is an intrinsic spatial dimension in all area-wide programmes. The best way to operate at this geographic/spatial dimension is by combining geographic information systems (GIS) technology with aerial intervention tools (IAEA 2006). Until now, aircrafts have been widely used in AW-IPM implementation, and their deployment has major comparative advantages for those programmes operating over large areas of difficult topography and that lack road networks (Vreysen et al. 2007; Dyck et al. 2021). Although the technology of remotely piloted aircraft systems (RPAS) continues 
improving for many applications, it is already technically sufficiently mature to allow carrying out many of the activities of an AW-IPM operational programme by air. The term RPAS is the official International Civil Aviation Organization (ICAO) term for such aircraft, whereas terms such as unmanned aircraft systems (UAS) are being less used in view that regulations prescribe that all aircraft need to be piloted, even when the pilot is not on board (FAA 2017; CASA 2018). As the term drone, common in francophone countries, is increasingly identified with military applications, it is not used here.

The main current applications of RPAS in agriculture are air-borne scouting of field crops and of ranging livestock through remote sensing, as well as precision delivery systems and aerial spraying with low or ultra-low volumes in some crops. The advantages of the RPAS technology are mainly in the fields of safety, accuracy and cost efficiency. However, as it usually happens with technology involving a shift of paradigm in the way society deals with problems, the regulatory framework is not fully developed and has not evolved at the required speed. This has led some pioneers to develop applications with an ad hoc certificate of authorization (COA) or, in some cases, to operate at the fringes of the legal regulation. The future of RPAS will therefore depend as much on decisions made by regulators as it does on technological advances, and for example France's relatively permissive regulation has put it at the forefront of the agricultural use of unmanned aircrafts (The Economist 2017). In recent months, however, more appropriate regulatory frameworks have been adopted in different countries, clarifying the requirements for the operation of UAV and opening the field for commercial applications of RPAS, while at the same time, driving technology adaptation to the new regulations.

\section{THE TECHNOLOGY}

\subsection{Elements of a Remotely Piloted Aircraft System (RPAS)}

A RPAS is made of three main parts: the remote-control station, the datalink and the remotely piloted aircraft or (RPA) unmanned aerial vehicle (UAV) (Fig. 1). The control station contains all the elements that permit operators to manage the UAV flight. This includes the software that interacts with the aircraft via datalink, but also the computer (which can be just a tablet) and the joystick that controls the RPA in manual mode.

The datalink refers to the main elements that allow communications between the control station and the aircraft. The core element is the radio, which must use a frequency authorized by national authorities (for civil aviation purposes, usually $2.4 \mathrm{GHz}$ or 900 $\mathrm{MHz}$ for remote control, along with $5.8 \mathrm{GHz}$ for video and audio links) and can include helpful methods to avoid interferences, such as the "Frequency Hopping Spread Spectrum" (FHSS) technique. Communications can be digital or analogue: while the first provides higher quality, especially for video transmission, the range of the second one is higher for low-cost systems. The use of antennas and amplifiers should be considered too, especially when the payload and power capacity of the aircraft is too limited. For very long-range communications, it is highly recommended to use a tracking antenna: a directional antenna with embedded control actuators and installed encoders that automatically points to the aircraft with high precision, maximizing the communications range. 


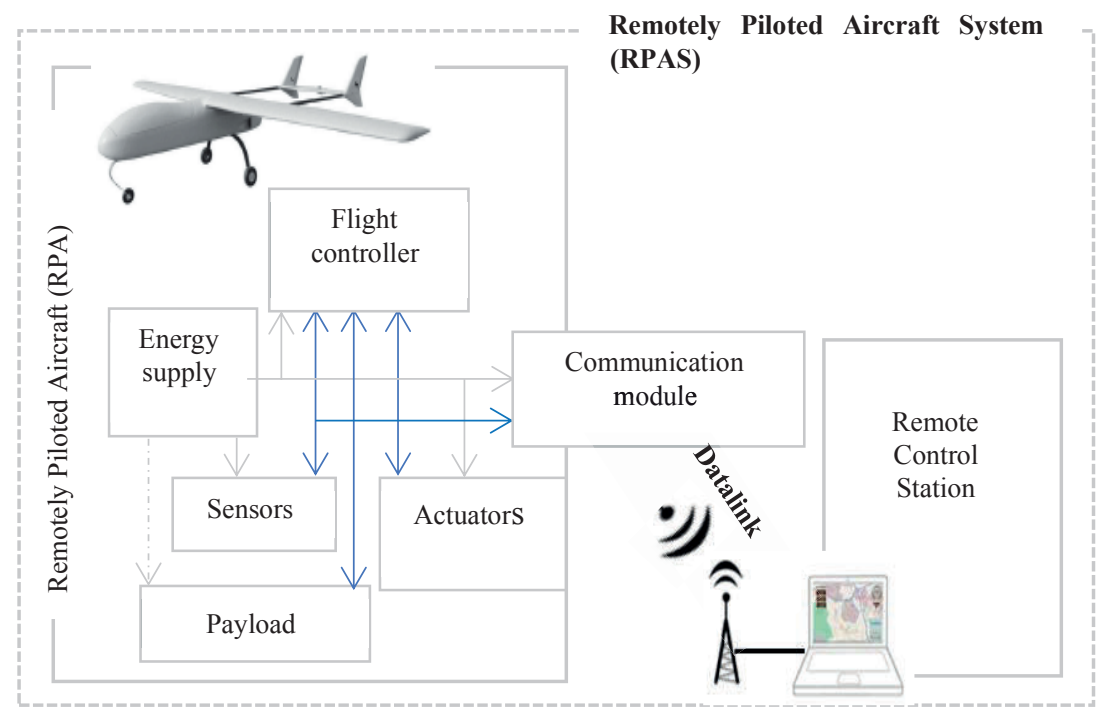

Figure 1. Main components of Remotely Piloted Aircraft Systems (RPAS) (modified after Wikipedia 2019).

Different options of unmanned vehicles are available to fulfil the required operation in the most efficient way: from fixed-wing aircrafts to multirotors, helicopters, blimps, parafoils or hybrid Vertical Take-Off and Landing (VTOL) platforms, among many others (Fig. 2).

There is also a wide variety of engines available for these vehicles, from electrical to fuel powered engines. Although not commonly used yet, remarkable progress has been achieved in the development of hydrogen fuel cell powered engines, which are expected to extend the flight endurance. The choice of the engine will depend on the autonomy requirements but also on the size and weight of the aircraft; sometimes altitude can be a limiting condition due to lower air density at high elevations above sea level, requiring for instance the use of electrical fuel injection (EFI) engines for higher efficiency. The payload capacity and flight duration are also key elements for the majority of operations and must be carefully balanced when selecting the RPA for any specific task.

Commonly related to the three mentioned elements of RPAS, autopilots are key in any unmanned operation, especially when the aircraft should perform autonomous missions without the constant control of operators. The most sophisticated autopilots have embed a suite of sensors and processors together with Line of Sight (LOS) and Beyond Radio Line of Sight (BRLOS) Machine to Machine (M2M) datalink radios, all with reduced size and weight to minimise the use of the payload capacity of the aircraft.

These autopilots usually permit the connection with external peripherals such as transponders and radars, increasing the capabilities of the platform during fully unmanned missions through the provision, for instance, of reliable and autonomous Detect \& Avoid (DAA) tools. These refer to the technology that provides to unmanned vehicles the capability to detect obstacles on their route (such as other aircrafts) and to immediately find a way to prevent collision. 
When they are aimed at professional purposes, autopilot systems must be developed according to international standards in order to be compliant with national regulations for the professional operation of RPAS.

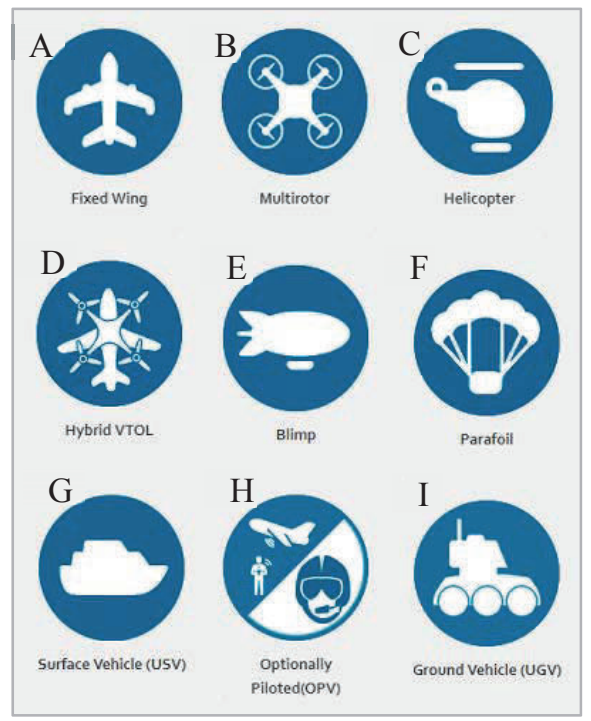

Figure 2. Types of unmanned vehicles: (A) Fixed-wing; (B) Multirotor; (C) Helicopter; (D) Hybrid Vertical Take-Off and Landing (VTol); (E) Blimp; (F) Parafoil; (G) Unmanned surface vehicle (USV); (H) Optionally piloted vehicle (OPV); and (I) Unmanned ground vehicle (UGV) (credit Embention).

\subsection{Safety Considerations}

In addition to the design and development of the RPAS according to aerial international standards, redundant systems greatly reduce the risk of failure. Redundancy usually is focused on the autopilot (normally with triple redundancy). Triple redundancy for autopilots refers to the inclusion of three autopilot units in the same flight controller. These three autopilots operate as if they were a single unit dealing with the control of the unmanned platform. A dissimilar arbiter (a piece of electronics included in the redundant autopilot) decides which of those three autopilots is in command attending to the efficiency and coherence of their orders. Therefore, in case any autopilot unit fails, there will be still two units capable to deal with the whole operation. For critical operations performed by large aircraft, such as originally manned helicopters that were adapted into unmanned platforms, redundancy is commonly extended to actuators, as long as the platform can tolerate the increase in weight caused by the redundant actuators and the budget of the project can deal with their price.

Autopilot systems have several configurable safety routines that can be triggered under specific situations. Some of these safety routines include landing if the battery/fuel is below a defined threshold of its capacity, go back to the take-off point if the datalink 
is lost, and reduce altitude if the wind speed is higher than a predefined value. Also, configurations aimed to end the flight in the safest possible way can be configured into the Flight Termination System (FTS): an arbiter microprocessor within the autopilot that activates the flight termination in case of failure of the main microprocessor or any of the motors (e.g. by releasing a parachute).

The most sophisticated autopilot systems also include sensors such as radars, lidars and/or transponders that permit the use of DAA technologies. An officially certified DAA system is currently mandatory to operate beyond visual line of sight in most of the countries, but due to the novelty and impact of this technology in the industry, currently the certification process of this kind of system consists of a series of negotiations with national authorities who normally request clear and irrefutable proof about the reliability of the system.

\section{CURRENT APPLICATIONS OF THE RPAS TECHNOLOGY IN AGRICULTURE}

Precision agriculture, construction and public safety are the most promising commercial and civil aviation markets for RPAS (The Economist 2017). RPAS are used in agriculture for low altitude remote sensing (LARS) of crop conditions with multi-spectral and hyperspectral cameras. High spatial resolution information on crop hydric stress (Berni et al. 2009), crop vegetation index (Primicerio et al. 2012), weed detection (Hardin et al. 2007) and yield mapping (Swain et al. 2010) can be obtained with the proper data acquisition and analysis.

When compared to satellite remote sensing, RPAS-based remote sensing has a higher spatial and temporal resolution, lower costs and is not affected by cloud coverage among other advantages (Nansen and Elliott 2016). However, the calibration of the sensors under field conditions and post-processing of the acquired information remain complex and require high level of expertise.

After analysing the data collected by RPAS, farmers can tailor their use of irrigation, pesticides, herbicides and fertilizers, applying by ground variable rate technologies and following the principles of precision-agriculture (Zhang and Kovacs 2012).

At the research level, remote sensing with RPAS has also been used to detect host plant responses to insect infestations, like the analysis of the variation in the vegetation index (Normalized Difference Vegetation Index or NDVI) in wheat fields caused by an attack of fall armyworm Spodoptera frugiperda J.E. Smith (Zhang et al. 2014).

RPAS are also used for low and ultra-low volume aerial spraying of insecticides and herbicides. In Japan, one of the world-leading manufacturers of agriculture RPAS (Yamaha Motor Company) estimates that about one million ha of rice, around 35\% of the Japanese rice fields, are currently sprayed with their unmanned helicopters (Yamaha 2017).

In China, several commercial companies offer off-the-shelf commercial RPAS models for crop spraying with variable tank capacities and spraying methods, from thermal fogging to electrostatic spraying (DJI 2017; Joyance 2017). The mission planning and operation of these spraying RPAS is relatively simple thanks to dedicated remote controllers and software. Variable rates of pesticides, fertilizers and herbicides can be applied. 


\section{REGULATORY FRAMEWORK}

\subsection{Classification of Remotely Piloted Aircrafts and Operations}

Although different legal frameworks exist in each country/region, most of the existing regulations classify the RPAs in relation to their weight (ICAO 2015; and other regulations listed in Table 1):

1. Micro-RPA if less than $2 \mathrm{~kg}$ of maximum take-off mass (MTOM)

2. Small RPA between 2 and $25 \mathrm{~kg}$ of MTOM and

3. Large RPA between 25 and $150 \mathrm{~kg}$ of MTOM.

They also classify them in relation to the type of operation:

1. Within the visual line of sight (VLOS) when the distance to the operator is less than $500 \mathrm{~m}$ with good visibility conditions and flight elevation below $120 \mathrm{~m}$

2. Beyond visual line of sight (BVLOS) and flight elevation below $150 \mathrm{~m}$ over the ground (also called Very Low Level or VLL operations)

3. Beyond visual line of sight (BVLOS) and flight elevation above $150 \mathrm{~m}$ over the ground; and

4. A fourth and intermediate class, which is the Extended Visual Line of Sight (EVLOS) for those operations where the main pilot has no visual contact with the RPA, but other pilots/observers, in communication with the main one, are capable to see it.

\subsection{Different Regulations in Each Country}

The regulatory framework for the operation of RPAs is not fully developed in all the countries and not fully harmonized across the countries and regions. However, some common ground among the regulations of different countries can be found:

1. Regarding the weight of the RPAs, those over $2 \mathrm{~kg}$ MTOM must be operated by certified operators; those over $25 \mathrm{~kg}$ MTOM must be registered and follow either a riskbased approach or obtain a type certificate.

2. Regarding the type of operation, RPAs should be operated within the VLOS. Operations BVLOS are only allowed under especial conditions (when the aircraft is under $2 \mathrm{~kg}$, when operating in special areas of the airspace, or when using DAA technology or UAS Traffic Management (UTM)/U-Space systems (set of new services relying on a high level of digitalisation and automation of functions and specific procedures designed to support safe, efficient and secure access to airspace for large numbers of drones) (SESAR-JU 2019).

3. Operations over restricted areas (e.g. populated areas) must be performed by platforms with a certificate of airworthiness and also with permission from public authorities.

4. RPAS operators and RPAs above $250 \mathrm{~g}$ must be registered.

5. Most, if not all, RPAS operations must be insured.

Some examples of the relevant regulations for RPAS operators in different countries can be found in Table 1. Due to the early stage of the unmanned industry and regulations, waivers by the competent national authority against these regulations are possible. 
Table 1. Regulatory framework for the use of remotely piloted aerial systems (RPAS) in different countries/regions

\begin{tabular}{|c|c|c|c|}
\hline $\begin{array}{l}\text { Country / } \\
\text { Region }\end{array}$ & Organism & Document & $\begin{array}{l}\text { Release } \\
\text { Date }\end{array}$ \\
\hline Australia & $\begin{array}{l}\text { Civil Aviation Safety Authority } \\
\text { (CASA 2018) }\end{array}$ & $\begin{array}{l}\text { - General information } \\
\text { - Regulation: Direction-operation of certain } \\
\text { unmanned aircraft }\end{array}$ & $2017-10$ \\
\hline $\begin{array}{l}\text { European } \\
\text { Union }\end{array}$ & $\begin{array}{l}\text { European Aviation Safety } \\
\text { Agency (EASA 2017) }\end{array}$ & $\begin{array}{l}\text { - General information } \\
\text { - Opinion No 01/2018 Introduction of a } \\
\text { regulatory framework for the operation of } \\
\text { unmanned aircraft systems in the 'open' and } \\
\text { 'specific' categories }\end{array}$ & $2017-05$ \\
\hline Japan & $\begin{array}{l}\text { Civil Aviation Bureau } \\
\text { (CAB 2016) }\end{array}$ & - General information & $2015-10$ \\
\hline Mexico & $\begin{array}{l}\text { Dirección General de } \\
\text { Aeronáutica Civil } \\
\text { (DGAC 2017) }\end{array}$ & $\begin{array}{l}\text { - General Information } \\
\text { - Regulation: CO AV-23/10 R4 que establece } \\
\text { requerimientos para operar un sistema de } \\
\text { aeronave pilotada a distancia (RPAS) }\end{array}$ & 2017-07 \\
\hline Spain & $\begin{array}{l}\text { Agencia Estatal de Seguridad } \\
\text { Aérea (AESA 2018) }\end{array}$ & $\begin{array}{l}\text { - General information } \\
\text { - Regulation: Utilización de RPAS }\end{array}$ & $2017-12$ \\
\hline USA & $\begin{array}{l}\text { Federal Aviation Administration } \\
\text { (FAA 2017) }\end{array}$ & $\begin{array}{l}\text { - General information } \\
\text { - JO 7200.23: Unmanned Aircraft Systems } \\
\text { (UAS) }\end{array}$ & 2016-10 \\
\hline
\end{tabular}

\subsection{Certificate of Airworthiness}

The certificate of airworthiness is issued by the competent agency in charge of aviation safety in each country. Considering that it depends on national rules, this certificate may be mandatory if the maximum take-off mass (MTOM) of the remotely piloted aircraft is over $25 \mathrm{~kg}$, but there are other situations where the certificate may be requested such as performing operations over populated areas or if the operation will take place BVLOS.

The request for a certificate needs to include every element of the RPAS, which includes a study about the risk of operating the system, the results of the tests made to the autopilot (hardware and software) and the structure of the aircraft and its resistance to harsh environments, such as extreme temperatures, humidity or dust conditions.

\subsection{Pilots Qualifications}

Regulations in most countries require RPAS pilots to be of legal age and their medical condition certified by an official aeronautical centre. In addition, the pilot must have the theoretical knowledge (an official license is required, such as an ultralight flight pilot license) and the practical knowledge on the specific RPAS (obtained from the manufacturer of the RPAS or by an organization delegated by the manufacturer) (ICAO 2015; and other regulations listed in Table 1). 


\section{ADVANTAGES AND OPPORTUNITIES FOR RPAS IN AW-IPM WITH THE CURRENT LEGAL REGULATIONS}

One of the main advantages of the technology is in the field of safety, avoiding the risks for pilots inherent to any operation with manned aircrafts in agriculture. In case of accident, the severity of harm is minimised thanks to the absence of an onboard pilot and the lower kinetic energy of the aircraft.

Accuracy of the operations is very high (the same as in regular aircrafts), since the mission events are preconfigured based on geographic information and triggered automatically during the flight by the GPS information, avoiding human errors during operation. The parameters of the operation, such as the dose to be applied per surface unit during an aerial spraying operation or insect release, are controlled directly by the microprocessors that will adjust the actuators to obtain a constant value regardless of the variations of the flight speed (DJI 2017).

Cost-efficiency is also a major advantage of the RPAS technology thanks to the relatively low investment, maintenance and operational costs. However, cost-efficiency varies depending on the scale of the operation and detailed analysis should be conducted on a case by case basis.

Within the current legal framework, some of the activities that are part of the AWIPM programmes for the control of different pest insects can be carried out using RPAS (Table 2). Some of the operations, such as the suppression of fruit fly hotspots, do not require a specific authorization from the civil aviation authority (CAA). Others, like those who require operation BVLOS, require a special operation permit by the relevant CAA based on a specific operations risk assessment (JARUS 2017).

\subsection{Suppression of Fruit Fly Hotspots and Mosquito Larval Breeding Sites}

One common activity in AW-IPM programmes against fruit flies is the suppression of hotspots by bait-spraying. Hotspots are detected and delimited by weekly trapping surveys and later normally treated by ground with bait sprays. For example, the Mediterranean fruit fly, Ceratitis capitata (Wiedemann) control programme in Valencia (Spain) uses a fleet of all-terrain vehicles (ATV) equipped with ground sprayers for this purpose (Argilés and Tejedo 2007) (Fig. 3). However, the low volume of insecticide required by bait sprays compared to cover sprays and the limited size of the area to be treated - the size of hotspots is usually some tens of ha - make this task technically suitable for aerial application by RPAS.

Currently, off-the-shelf RPAS for spraying have been developed by several commercial companies with specific software and remote controller for this task. From the regulation point of view, the operation in VLOS over commercial crops outside restricted areas and with a maximum take-off mass below $25 \mathrm{~kg}$ exempt this application in most countries of the requirement for a specific permit or certificate of airworthiness from the national civil aviation authorities. The area covered per day can range between 25 to 50 ha depending on the insecticide application specifications, which is several times higher than can be achieved by ground spraying. 
Table 2. Summary of technical parameters for different RPAS applications

\begin{tabular}{|c|c|c|c|c|c|c|c|c|c|c|c|}
\hline \multirow[t]{2}{*}{ Activity } & \multicolumn{2}{|c|}{ Weight of adults } & \multicolumn{3}{|c|}{ Release density } & \multicolumn{2}{|c|}{$\begin{array}{l}\text { Biomass of insects } \\
\text { per surface }\end{array}$} & \multicolumn{2}{|c|}{$\begin{array}{c}\text { Area to be } \\
\text { covered per flight }\end{array}$} & \multicolumn{2}{|c|}{ Swath widths } \\
\hline & $\min$ & $\max$ & \multicolumn{2}{|l|}{$\min$} & $\max$ & $\min$ & $\max$ & $\min$ & $\max$ & $\min$ & $\max$ \\
\hline $\begin{array}{l}\text { Release of sterile } \\
\text { Aedes mosquitoes }\end{array}$ & $0.9 \mathrm{mg}$ & $\begin{array}{l}1.1 \\
\mathrm{mg}\end{array}$ & 1000 males/ha & \multicolumn{2}{|c|}{2000 males/ha } & $\begin{array}{r}90 \\
\mathrm{~g} / \mathrm{km}^{2}\end{array}$ & $\begin{array}{r}220 \\
\mathrm{~g} / \mathrm{km}^{2}\end{array}$ & 40 ha & 60 ha & $75 \mathrm{~m}$ & $100 \mathrm{~m}$ \\
\hline $\begin{array}{l}\text { Release of sterile } \\
\text { tsetse flies }\end{array}$ & $20 \mathrm{mg}$ & $30 \mathrm{mg}$ & $0.5 \mathrm{males} / \mathrm{ha}$ & \multicolumn{2}{|c|}{$1.0 \mathrm{males} / \mathrm{ha}$} & $1 \mathrm{~g} / \mathrm{km}^{2}$ & $3 \mathrm{~g} / \mathrm{km}^{2}$ & 3000 ha & $\begin{array}{r}8000 \\
\text { ha }\end{array}$ & $\begin{array}{r}300 \\
\mathrm{~m}\end{array}$ & $400 \mathrm{~m}$ \\
\hline $\begin{array}{l}\text { Fruit fly hotspot bait } \\
\text { spraying }\end{array}$ & - & - & - & \multicolumn{2}{|r|}{-} & - & - & 3 ha & 6 ha & $8 \mathrm{~m}$ & $10 \mathrm{~m}$ \\
\hline \multirow[t]{2}{*}{ Activity } & \multicolumn{2}{|c|}{$\begin{array}{l}\text { Flight distance } \\
\text { (without ferry) }\end{array}$} & \multirow{2}{*}{$\begin{array}{c}\text { Speed } \\
\text { during } \\
\text { operation }\end{array}$} & \multicolumn{2}{|c|}{$\begin{array}{l}\text { Flight time } \\
\text { (without ferry) }\end{array}$} & \multirow[t]{2}{*}{ Payload } & \multirow{2}{*}{\multicolumn{2}{|c|}{ Type of aircraft }} & \multirow[t]{2}{*}{$\begin{array}{l}\text { Type of } \\
\text { operation }\end{array}$} & \multirow{2}{*}{\multicolumn{2}{|c|}{$\begin{array}{c}\text { Specific } \\
\text { authorization by } \\
\text { relevant CAA }\end{array}$}} \\
\hline & $\min$ & $\max$ & & $\min$ & $\max$ & & & & & & \\
\hline $\begin{array}{l}\text { Release of sterile } \\
\text { Aedes mosquitoes }\end{array}$ & $5.3 \mathrm{~km}$ & $6.0 \mathrm{~km}$ & $10 \mathrm{~m} / \mathrm{s}$ & $9 \min$ & $10 \mathrm{~min}$ & $300 \mathrm{~g}$ & \multicolumn{2}{|c|}{$\begin{array}{l}\text { rotationary; } \\
\text { micro }\end{array}$} & $\begin{array}{l}\text { VLOS; } \\
\text { urban } \\
\text { area }\end{array}$ & \multicolumn{2}{|c|}{ mandatory } \\
\hline $\begin{array}{l}\text { Release of sterile } \\
\text { tsetse flies }\end{array}$ & $100 \mathrm{~km}$ & $\begin{array}{l}200 \\
\mathrm{~km}\end{array}$ & $20 \mathrm{~m} / \mathrm{s}$ & $83 \mathrm{~min}$ & $\begin{array}{l}167 \\
\min \end{array}$ & $900 \mathrm{~g}$ & \multicolumn{2}{|c|}{$\begin{array}{l}\text { fixed-wing/ } \\
\text { helicopter; } \\
\text { medium }\end{array}$} & $\begin{array}{l}\text { BVLOS; } \\
\text { rural area }\end{array}$ & \multicolumn{2}{|c|}{ mandatory } \\
\hline $\begin{array}{l}\text { Fruit fly hotspot } \\
\text { bait spraying }\end{array}$ & $3.8 \mathrm{~km}$ & $6 \mathrm{~km}$ & $8 \mathrm{~m} / \mathrm{s}$ & $8 \mathrm{~min}$ & $13 \mathrm{~min}$ & $10 \mathrm{~kg}$ & \multicolumn{2}{|c|}{$\begin{array}{l}\text { rotationary; } \\
\text { medium }\end{array}$} & $\begin{array}{l}\text { VLOS; } \\
\text { rural area }\end{array}$ & \multicolumn{2}{|c|}{ exempted } \\
\hline
\end{tabular}


Similarly, mosquito larvicides can be applied aerially to larval breeding areas, replacing the current ground and helicopter treatments, as demonstrated in the ongoing tests by L'Entente Interdépartementale pour la Démoustication du Littoral Méditerranéen in France (EID Méditerranée 2018).
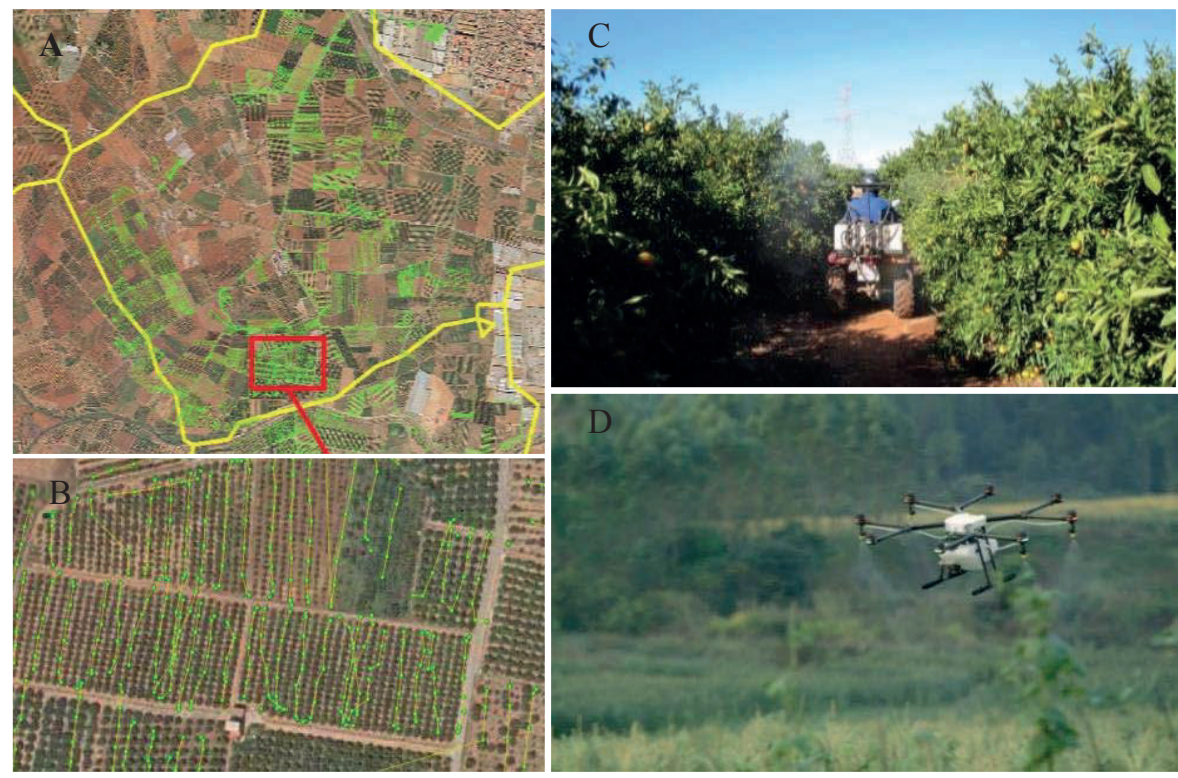

Figure 3. (A) Delimiting the extent of hot spots with GIS-based field surveys of monitoring traps. (B) Green tracks showing the bait spray ground treatment done in different citrus orchards; only orchards with a ripening variety are treated. (C) ATV applying a bait spray treatment by ground.

(D) Spraying RPAS with a 10 litre tank.

\subsection{Release of Sterile Aedes Mosquitoes in SIT Programmes}

The weight of adult Aedes spp. mosquitoes is low (ca. $1 \mathrm{mg}$ ). They also have a low dispersal behaviour, which compared to other pests, makes it possible to apply area-wide control programmes over relatively small urban areas. These two conditions make the aerial release of sterile mosquito males technically feasible using RPAS.

Flying over the urban or peri-urban scenario typical of an Aedes spp. mosquito control programmes, however, requires a mandatory permit and certificate of airworthiness for the specific operation by the local aerial safety agency. To facilitate obtaining these, the use of micro-RPAS, i.e. under $2 \mathrm{~kg}$ of maximum take-off mass, is advised.

An aerial platform of less than $1 \mathrm{~kg}$, including the payload with the release machine and an insect cargo of around 75000 sterile males, can suffice to release mosquitoes in VLOS over 50 ha with a flight duration of less than ten minutes per flight and a flight elevation under $100 \mathrm{~m}$. 


\subsection{Release of Sterile Tsetse Flies in SIT Programmes}

Tsetse fly SIT programmes are applied at a scale of very large areas, usually covering several hundred or thousand $\mathrm{km}^{2}$ of rural landscape (Feldmann et al. 2021). The required release density of sterile males is only between 50 to 100 sterile males per $\mathrm{km}^{2}$ and per week (equivalent to 1 to $3 \mathrm{~g}$ of insects per $\mathrm{km}^{2}$ and per week, depending on the tsetse species). This is a very low release rate when compared to other pest species, namely fruit flies (Hendrichs et al. 2021). Release swaths of 300-400 $\mathrm{m}$ are common in view that tsetse flies disperse sufficiently between flight lines.

To conduct the aerial releases under these conditions, a remotely piloted aircraft with a flying endurance of at least $100 \mathrm{~km}$ and a payload of approximately $1 \mathrm{~kg}$ for the chilled insect release machine and the sterile insect cargo is needed (for an example see Fig. 4). Several fixed-wing and helicopter models currently available on the market with a MTOM below $25 \mathrm{~kg}$ meet these technical requirements. The release operation will necessarily be BVLOS, and thus will require specific authorization by the local aerial safety agency. In addition, the take-off and landing point will need to be as close as possible or within the release area to save ferry flying time, which may require a field insectary.

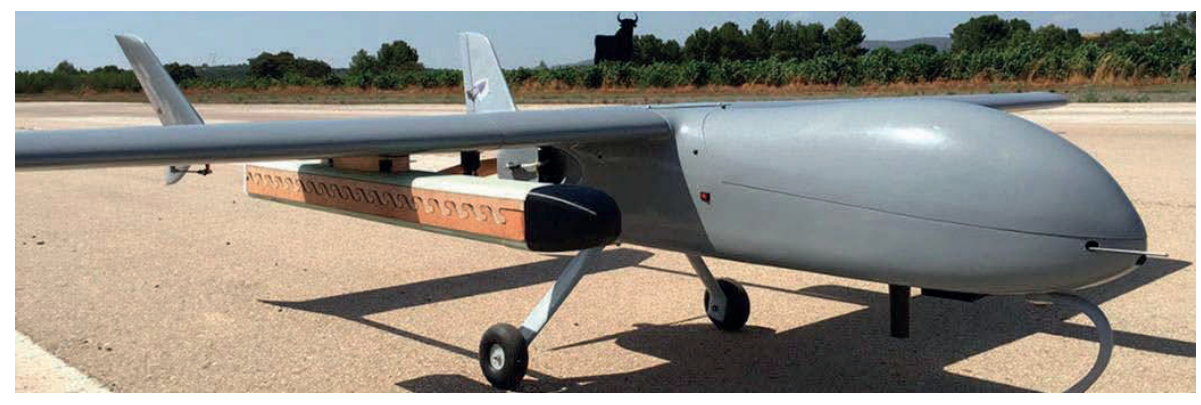

Figure 4. Unmanned aircraft developed for the Southern Tsetse Eradication Project in Ethiopia. The pods under the wings carry the sterile tsetse males in chilled conditions.

\subsection{Release of Parasitoids in AW-IPM Programmes}

Several AW-IPM programmes release parasitoids to control different pests, such as the aerial releases of chilled Diachasmimorpha longicaudata (Ashmead) parasitoids massproduced by the Moscafrut programme in Mexico to control Anastrepha ludens (Loew) and An. obliqua (Macquart) fruit flies (Montoya et al. 2007); or ground releases in Costa Rica of Spalangia endius Walker to control the cattle pest Stomoxys calcitrans (L.) by Costa Rica's National Institute of Agricultural Technology, Innovation and Transfer (INTA) (Solorzano-Arroyo et al. 2017). The release of these tiny wasps can be carried out with RPAs under $25 \mathrm{~kg}$, although to be more cost-effective, the operation needs to be BVLOS, and therefore requires the specific authorization by the local aerial safety agency based on a specific operation risk assessment (JARUS 2017).

In Mexico, aerial releases of Tamarixia radiata Waterston, the parasitoid of Diaphorina citri Kuwayama, the vector of Huanglongbing, are being conducted with an 
RPAS by the company Mubarqui within the area-wide programme of the Servicio Nacional de Sanidad, Inocuidad y Calidad Agroalimentaria (SENASICA) that manages the citrus greening programme in Mexico (García-Ávila et al., this volume).

\subsection{Release of Sterile Fruit Flies in SIT Programmes}

The release of sterile fruit flies in SIT operational programmes is carried out with small aircrafts covering tens of thousands of ha per flight and with a cargo above $100 \mathrm{~kg}$ of biomass (FAO/IAEA 2017). RPAS doesn't seem suited for this job, since this would require large RPAs with a complex certification process.

Small pilot projects could possibly benefit of RPAS for aerial releases provided they apply a shift of strategy for the aerial releases, e.g. several short flights with a low load of sterile insects from a mobile base within the release area.

\subsection{Strategy and Logistics for the Releases of Sterile Insects}

As described, RPAS can potentially be used in some AW-IPM programmes to release sterile insects. To do so, some adaptations to the current release procedures are needed to compensate for the lower payload and endurance capacities of the RPA aircraft. Currently, large numbers of sterile insects are released in SIT operational programmes by manned aircrafts in a single flight covering large areas (for example, tens of millions of sterile insects over hundreds of $\mathrm{km}^{2}$ in the case of fruit fly programmes).

If RPAS are to be used for the aerial release of sterile insects, multiple and shorter flights are needed for the same purpose. Currently, the manned aircrafts take-off from a runway located close to the sterile fly emergence and release facility. Release by RPAS will require that the sterile insects be transported by ground to the take-off point within the release area, or at least in the very close vicinity. This will require the use of a mobile take-off station from which the RPAS is operated and where sterile insects are kept under chilled conditions waiting for their turn to be released.

\subsection{Release Machines}

Apart from the mandatory requirements of using light materials, the release machines also require a chilling system capable of maintaining the temperature between $4^{\circ} \mathrm{C}$ and $8^{\circ} \mathrm{C}$ in the insect holding container, depending on the insect species, during the flight. Passive chilling systems like those based on the use of phase-change materials (PCM) can provide such conditions at a low payload cost. Relative humidity must be kept under the dew point to avoid condensation on the surface of the insect bodies. Some insects like mosquitoes or some species of parasitoid wasps have fragile legs and antennae and require higher holding temperatures and special equipment to avoid mechanical damage by compaction and vibrations during the flight and by friction while going through the release mechanism (Montoya et al. 2012).

Accurate releases with variable release rates can be continuous, along a flight path or discrete, focused on individual waypoints with predefined coordinates. 


\section{CONCLUSIONS}

The RPAS technology is widely and increasingly used in agriculture for remote sensing and pesticide spraying of crops, mainly at the level of individual larger farms. However, RPAS are still not routinely used in operational AW-IPM programmes, such as fruit fly SIT programmes, because the scale of these programmes is usually too large for the current technical and regulatory limitations of RPAS.

Nevertheless, as discussed in this review, the legal regulations recently approved in several countries have opened the possibility to use the existing commercial RPAS technology for some of the field activities of AW-IPM programmes. This is the case of the chemical treatment of hotspots in fruit flies or mosquito control programmes, providing high application accuracy.

Some other applications, such as the release of sterile males of tsetse or mosquitoes, respectively over large or urban areas, require a specific risk assessment prior to the authorization by the relevant civil aviation authority in the country. In this regard, the development of the novel DAA technology and UTM/U-Space systems, and their official certification, will facilitate the authorization of applications and operations beyond the pilot VLOS, as commonly needed in area-wide programmes.

\section{REFERENCES}

(AESA) Agencia Estatal de Seguridad Aerea. 2018. Drones legal framework. Spanish Aviation Safety Agency. Ministerio de Fomento, Gobierno de España, Spain.

Argilés, R., and J. Tejedo. 2007. La lucha de la mosca de la fruta mediante la técnica del insecto estéril en la Comunitat Valenciana. Levante Agrícola 385: 157-162.

Berni, J. A. J., P. J. Zarco-Tejada, L. Suarez, V. Gonzalez-Dugo, and E. Fereres. 2009. Remote sensing of vegetation from UAV platforms using lightweight multispectral and thermal imaging sensors. International Archives Photogrammetry, Remote Sensing and Spatial Information Science: 38 (6): 6.

(CAB) Civil Aviation Bureau. 2016. Japan's safety rules on Unmanned Aircraft (UA)/Drone. Japan Ministry of Land, Infrastructure, Transport and Tourism, Tokyo, Japan.

(CASA) Civil Aviation Safety Authority. 2018. Flying drones/remotely piloted aircraft in Australia. Australian Government, Canberra, Australia.

(DGAC) Dirección General de Aeronáutica Civil. 2017. Circular Obligatoria CO AV-23/10 R4 que establece los requerimientos para operar un sistema de aeronave pilotada a distancia (RPAS). Secretaria de Comunicaciones y Transporte, México. 55 pp.

DJI (Da-Jiang Innovations Science and Technology Co., Ltd). 2017. Agras MG-1, DJ's first agricultural drone. DJI Company, Hangzhou, China.

Dyck, V. A., J. Hendrichs, and A. S. Robinson (eds.). 2021. Sterile Insect Technique - Principles and practice in Area-Wide Integrated Pest Management. Second Edition. CRC Press, Boca Raton, Florida, USA. 1200 pp.

(EASA) European Aviation Safety Agency. 2017. Notice of proposed amendment 2017-05 (A): Introduction of a regulatory framework for the operation of drones. European Union. $128 \mathrm{pp}$.

(EID Méditerranée) Entente Interdépartemental pour la Démoustication du Littoral Méditerranéen. 2018. Traitement drone bientôt opérationnel? 4 janvier 2018. Montpellier, France.

(FAA) Federal Aviation Administration. 2017. Unmanned aircraft systems (UAS). Regulations \& policies. United States Department of Transportation, Washington, DC, USA.

(FAO/IAEA) Food and Agriculture Organization of the United Nations/International Atomic Energy Agency. 2017. Guideline for packing, shipping, holding and release of sterile flies in area-wide fruit fly control programmes. J. L. Zavala-López, and W. R. Enkerlin (eds.). Second edition, Rome, Italy. 140 pp. 
Feldmann, U., V. A. Dyck, R. C. Mattioli, and J. Jannin. 2021. Potential impact of tsetse fly control involving the Sterile Insect Technique, pp. 1051-1088. In V. A. Dyck, J. Hendrichs, and A. S. Robinson (eds.), Sterile Insect Technique - Principles and practice in Area-Wide Integrated Pest Management. Second Edition. CRC Press, Boca Raton, Florida, USA.

Hardin, P. J., M. W. Jackson, V. J. Anderson, and R. Johnson. 2007. Detecting squarrose knapweed (Centaurea virgata Lam. Ssp. Squarrosa Gugl.) using a remotely piloted vehicle: A Utah case study. GIScience \& Remote Sensing 44: 203-219.

Hendrichs, J., P. Kenmore, A. S. Robinson, and M. J. B. Vreysen. 2007. Area-Wide Integrated Pest Management (AW-IPM): Principles, practice and prospects, pp. 3-33. In M. J. B. Vreysen, A. S. Robinson, and J. Hendrichs (eds.), Area-wide control of insect pests: From research to field implementation. Springer, Dordrecht, The Netherlands.

Hendrichs, J., M. J. B. Vreysen, W. R. Enkerlin, and J. P. Cayol. 2021. Strategic options in using sterile insects for Area-Wide Integrated Pest Management, pp. 839-882. In V. A. Dyck, J. Hendrichs, and A.S. Robinson (eds.), Sterile Insect Technique - Principles and practice in Area-Wide Integrated Pest Management. Second Edition. CRC Press, Boca Raton, Florida, USA.

(IAEA) International Atomic Energy Agency. 2006. Designing and implementing a Geographical Information System: A guide for managers of area-wide pest management programmes. Joint FAO/IAEA Programme of Nuclear Techniques in Food and Agriculture. IAEA, Vienna, Austria.

(ICAO) International Civil Aviation Organization. 2015. Manual on Remotely Piloted Aircraft Systems (RPAS). Doc 10019 AN/507. Montréal, Quebec, Canada.

(JARUS) Joint Authorities for Rulemaking of Unmanned Systems. 2017. Guidelines on Specific Operations Risk Assessment. Document JAR-DEL-WG6-D.04. 48 pp.

Joyance. 2017. Spraying drones. Joyance Company, Shandong, China.

Montoya, P., J. Cancino, and L. Ruiz. 2012. Packing of fruit fly parasitoids for augmentative releases. Insects 3: 889-899.

Montoya, P., P. López, J. Cruz, F. López, C. Cadena, J. Cancino, and P. Liedo. 2017. Effect of Diachasmimorpha longicaudata releases on the native parasitoid guild attacking Anastrepha spp. larvae in disturbed zones of Chiapas, Mexico. BioControl 62: 581-593.

Montoya, P., J. Cancino J., M. Zenil, G. Santiago, and J. M. Gutierrez. 2007. The augmentative biological control component in the Mexican National Campaign against Anastrepha spp. fruit flies, pp. 661-670. In M. J. B. Vreysen, A. S. Robinson, and J. Hendrichs (eds.), Area-wide control of insect pests. Springer, Dordrecht, the Netherlands.

Nansen, C., and N. Elliott. 2016. Remote sensing and reflectance profiling in entomology. Annual Review of Entomology 61: 139-158.

Primicerio, J., S. F. D. Gennaro, E. Fiorillo, L. Genesio, E. Lugato, A. Matese, and F. P. Vaccari. 2012. A flexible unmanned aerial vehicle for precision agriculture. Precision Agriculture 13: 517-523.

(SESAR-JU) Single European Sky Air Traffic Management Research Joint Undertaking. 2019. U-space. European Commission for Transport. Bietlot, Belgium.

Swain, K. C., S. J. Thomson, and H. P. W. Jayasuriya. 2010. Adoption of an unmanned helicopter for low altitude remote sensing to estimate yield and total biomass of a rice crop. Transactions of the American Society of Agricultural and Biological Engineers 53: 21-27.

Solorzano-Arroyo, J. A., H. Mena, R. Romero, J. Trevino, J. Gilles, C. Geden, C. Taylor, H. Skovgaard. 2017. Biological control of livestock pest biting fly Stomoxys calcitrans at agriculture pineapple residues using the parasitoid Spalangia endius reared on irradiated Mediterranean fruit fly: Assessment of parasitism in field and laboratory in Costa Rica. Abstracts of the Third FAO/IAEA International Conference on Areawide Management of Insect Pests. May 22-26, 2017, Vienna, Austria.

The Economist. 2017. The future of drones depends on regulation, not just technology. Engineers and regulators will have to work together to ensure safety as drones take to the sky. Technology Quarterly June 10, 2017. The Economist, London, UK.

Vreysen, M. J. B., A. S. Robinson, and J. Hendrichs (eds.). 2007. Area-wide control of insect pests: From research to field implementation. Springer, Dordrecht, The Netherlands. $789 \mathrm{pp}$.

Wikipedia. 2019. Unmanned aerial vehicle.

Yamaha. 2017. RMAX Type IG/Type II unmanned helicopter. Yamaha Motor Corporation, Iwata, Shizuoka, Japan.

Zhang, C., and J. M. Kovacs. 2012. The application of small unmanned aerial systems for precision agriculture: A review. Precision Agriculture 13: 693-712.

Zhang, C., D. Walters, and J. M. Kovacs. 2014. Applications of low altitude remote sensing in agriculture upon farmers' requests - A case study in northeastern Ontario, Canada. PLoS One 9(11): e112894. 